\title{
Optimization of sunflower oil bleaching parameters: using Response Surface Methodology (RSM)
}

\author{
Leila SEDAGHAT BOROUJENI ${ }^{1}$, Mehrdad GHAVAMI ${ }^{1}$, Zahra PIRAVI VANAK ${ }^{2 *}$ (D), \\ Abdollah GHASEMI PIRBALOUTI ${ }^{3}$
}

\begin{abstract}
Bleaching is an important part of the oil refining process, in which pigments, impurities, traces of metals, and oxidative-molecular components of oils are removed. In this regard, the optimization of bleaching conditions can be effective to increase oil quality. In this study, de-gummed and neutralized sunflower oil was bleached at $80,90,100,110$, and $120^{\circ} \mathrm{C}$ for $15,25,35,45$, and 55 min by acid-activated bleaching clay with the concentrations of $0.4,0.6,0.8,1$, and $1.2 \%$ under laboratory conditions. At that point, peroxide, anisidine, plus Totox values, free fatty acid content, Rancimat, and specific UV absorption at 232 and $270 \mathrm{~nm}$ were analyzed via the RSM method. The model optimization using the RSM method revealed that the optimal conditions were $37.31 \mathrm{~min}$, temperature $92.7^{\circ} \mathrm{C}$, and clay concentration $1.18 \%$; this circumstance can meet $86.7 \%$ of the expectations as could be met for reducing the factors effective for oxidization during bleaching.
\end{abstract}

Keywords: bleaching process; optimization; response surface methodology; sunflower oil.

Practical Application: Using RSM as a method for optimizing bleaching operation can led to find the best combination of bleaching parameters to reduce resource consumption as well as increasing process capacity due to time adjustment.

\section{Introduction}

Crude vegetable oils contain impurities that, in addition to creating unpleasant flavors and tastes, can have a harmful effect on consumer health. Therefore, oil refining is necessary to remove undesirable compounds such as oxidation products and improve the quality (Didi et al., 2007). Auto-oxidation is a reaction with molecular oxygen through an autocatalytic mechanism, which is the main reaction involved in the oxidative degradation of fats (Fennema, 1996).

This mechanism consists of starting, propagating, and ending reactions that can be initiated periodically. The starting process produces free radicals from unsaturated fatty molecules. The radical fat is highly responsive and can react with atmospheric oxygen, producing a peroxy radical $\left(\mathrm{ROO}^{\circ}\right)$. In the propagation reactions, peroxy radicals respond with an unsaturated fat molecule, forming a hydroperoxide and a new unstable fat radical.

Once a new free radical is produced at each stage, more oxygen is combined in the system. The propagated radical fat then reacts with oxygen to produce another peroxy radical, resulting in an autocatalytic cyclic mechanism. Hydroxides, the early products of the fat autoxidation onset, are relatively unstable and may be decomposed into radicals that accelerate the propagation reactions. These are the main steps in the fat autoxidation process. This chain reaction is initiated and the final stage occurs only when two free radicals are combined into a non-radical product (Wanasundara \& Shahidi, 2005).
Bleaching is the most important process among the refining processes (Hatami et al., 2018). It is an absorption process that involves the use of the acid-activated clay to remove undesirable oil components (Nwabanne \& Ekwu, 2013). Some oils may contain colored compounds that are not desired by the consumer; therefore, they should be bleached to improve their color (Mukasa-Tebandeke et al., 2014). The color improvement is due to the removal of organic compounds such as carotenoids, particularly $\beta$-carotene and their derivatives, xanthophylls, chlorophylls, pheophytins, tocopherols, gossypol, and their degradation products; these can all transmit an undesirable color to oil (Okolo \& Adejumo, 2014).

Thus, the optimization of bleaching parameters, which mainly include the temperature, time, and percentage of the bleaching clay, is necessary to avoid harmful effects in the next steps and during the shelf life.

Response surface methodology (RSM) is a useful model to study the effect of different factors on the response factor (the intended factor) by simultaneously changing them and performing a limited number of experiments (Ajemba et al., 2013). RSM, which is based on polynomial analysis, is a set of mathematical and statistical techniques used to model and analyze issues when the subject under study is affected by several factors. 
The main objective of the response surface methodology is to identify the optimal conditions for the process. The use of practical statistical design techniques in the absorption process can lead to cost reduction (Moghaddam et al., 2018) as improving efficiency and closeness of the output results to the nominal values plus objectives; these, in turn, can reduce the variations and time required for modification, as well as the overall cost (Nwabanne \& Ekwu, 2013).

The current tendency in the edible oil industry is to assess the favorable conditions that can lead to the most effective bleaching. Therefore, the main aim of this study was to achieve the optimum conditions of bleaching process to avoid additional resources usage and obtain the best combination of time, temperature, and clay concentration in order to obtain the best bleached oil quality via the RSM.

\section{Materials and methods}

\subsection{Materials}

De-gummed and neutralized sunflower oil was obtained from Varamin 2 Company further acid-activated bleaching clay was prepared from Kanisaz Jam Company (PJS), Iran.

\subsection{Bleaching condition}

Laboratory bleaching of sunflower oil was carried out at the low rpm in a $1000 \mathrm{~mL}$ flask equipped with a thermometer and connected to a vacuum pump plus a nitrogen source. The characteristics of de-gummed and neutralized sunflower oil are: peroxide value 9.5 (meq $\mathrm{O}_{2} / \mathrm{kg}$ ), anisidine value 9.3, Totox value 28.3 , free fatty acid $0.08 \%$ oleic acid, Rancimat $1.2 \mathrm{~h}, A_{232 \mathrm{~nm}} 2.1, A_{268 \mathrm{~nm}} 1.4$. Bleaching was performed via an electromagnetic mixer with an adjustable heater equipped with a temperature cut-out and the thermocouple system.

A round-bottomed flask weighed the oils neutralized industrially; by mixing under the relative vacuum of 0.4 bars, they were heated. Acid-activated bleaching clay with the final concentrations of $0.4,0.6,0.8$, and 1 by $1.2 \%$ was added to the pre-heated oil at the temperature of about $60{ }^{\circ} \mathrm{C}$. Then, the oil was allowed to reach the bleaching temperature gradually $\left(80,90,100,110\right.$, and $\left.120{ }^{\circ} \mathrm{C}\right)$ with constant stirring under vacuum to completely disperse the bleaching clay.

After reaching the selected temperature, the heat was temporarily cut off to allow the temperature to drop to about $3{ }^{\circ} \mathrm{C}$. Heating was constant during the selected bleaching time $(15,25,35,45$, and $55 \mathrm{~min})$. At the end of the bleaching, the vacuum and heating system was turned off, and nitrogen was introduced. After bleaching, the mixture of the bleaching clay and the hot oil from the flask were filtered through a filter paper in the vacuum. A sample of bleached oil at $18^{\circ} \mathrm{C}$ was kept until the experiments were carried out (Skevin et al., 2012).

\subsection{Oxidative stability test by the Rancimat method}

Metrohm Switzerland 743 was used to evaluate the oil stability against oxidation. The oxidation state was determined at $110^{\circ} \mathrm{C}$. The air flow rate was $20 \mathrm{lit} / \mathrm{h}$. The analysis method was carried out by ISO 6886.2. According to this method,
$2.5 \mathrm{~g}$ of the fat sample was transferred to a special cell of the apparatus solvent and flow of filtered air was passed through the sample at $110^{\circ} \mathrm{C}$.

During the oil oxidation, the gases were released as the result of oxidation and transferred into a deionized water container. Then and there, the electrical conductivity of the aqueous solution was determined. The end of the high oxidation time was when the specific conductivity showed a rapid increase, due to the decomposition of carboxylic acids resulting from lipid oxidation and their absorption in deionized water (International Organization for Standardization, 1994).

\subsection{Peroxide value}

Peroxide value refers to the amount of oxygen reacting with the oil, resulting in the formation of hydroxides. Peroxide value was measured using ISO 3960: 2007 (International Organization for Standardization, 2007).

\subsection{Anisidine value}

Anisidine value of the oil samples was obtained via ISO 6885: 2006 (International Organization for Standardization, 2006).

\subsection{Totox value}

The Totox value was derived based on peroxide and anisidine values through Equation 1 (Fennema, 1996):

Totox value $=2 \times$ peroxide value + anisidine value

\subsection{UV specific absorption}

Specific UV absorbance at $232 \mathrm{~nm}$ and $270 \mathrm{~nm}$ was determined using ISO 3656: 2011 (International Organization for Standardization, 2011) by the Spectrometer Perkin Elmer Lambda20, USA.

\subsection{Free fatty acid}

Free fatty acid content in terms of oleic acid was determined using ISO 660: 2009 (International Organization for Standardization, 2009).

\subsection{Empirical optimization design and statistical analysis}

As described before, RSM can be used as a tool to achieve the optimal condition. Then, RSM with 3 factors including temperature $\left(80-120^{\circ} \mathrm{C}\right)$, time (15-55 min), bleaching clay concentration (0.4-1.2\%) at 5 levels $(-2,-1,0,1$, and 2$)$ and six replications at the central point $(17,16,15,12,11$, and 6 Nos) was used based on the central composite design (CCD). By considering these factors and their levels (20 runs processes), the statistical design table was developed.

In this design, $\mathrm{x}_{1}$ (time), $\mathrm{x}_{2}$ (temperature), and $\mathrm{x}_{3}$ (bleaching clay concentration) were the three independent factors also the peroxide value, anisidine value, Totox value, free fatty acid content, UV specific absorption, and Rancimat were the six dependent variables. In the RSM method, for each dependent 
variable, a model describing the main effects of the factors on each variable was developed separately. The multivariate model is shown in Equation 2:

$$
Y=\beta_{0}+\sum_{i=1}^{3} B i X i+\sum_{i=1}^{3} B i i X i X i+\sum_{i=1}^{3} B i j X i X j
$$

where: $\beta_{0}$ is the width from the origin; $B i$ is the $i^{\text {th }}$ linear regression factor; $B_{\mathrm{ii}}$ is the second order regression coefficient of the $\mathrm{i}^{\text {th }}$ factor; $\mathrm{B}_{\mathrm{ij}}$ is the interacting effect of the $\mathrm{i}^{\text {th }}$ factor plus the $\mathrm{j}^{\text {th }}$ one; and $\mathrm{Y}$ is the dependent variable. The model and the factors are shown in Table 1 (Mozafari et al., 2017).

\section{Results}

\subsection{Peroxide value}

According to ISO 3960: 2007 method, peroxide value was analyzed and the quadratic model was suggested for this index. Due to the simultaneous effect of temperature, time, and concentration of the bleaching clay on the peroxide value, it was determined that each factor, in addition to the independent effect, could interact with other factors. Also, the interaction of these three factors on the peroxide value was noteworthy.

In the ANOVA table (Table 2), the quadratic model was significant and the lack of fit factor was also insignificant.

Table 1. Design of the test by central composite design and the responses of the studied factors.

\begin{tabular}{|c|c|c|c|c|c|c|c|c|c|c|c|c|c|}
\hline \multirow{2}{*}{$A_{268 \mathrm{~nm}}$} & \multirow{2}{*}{$A_{232 \mathrm{~nm}}$} & \multirow{2}{*}{$\frac{\text { Rancimat }}{\mathrm{h}}$} & \multirow{2}{*}{$\begin{array}{c}\begin{array}{c}\text { Free fatty } \\
\text { acid }\end{array} \\
\text { \% oleic acid }\end{array}$} & \multirow{2}{*}{$\begin{array}{l}\text { Totox } \\
\text { value }\end{array}$} & \multirow{2}{*}{$\begin{array}{c}\text { Anisidine } \\
\text { value }\end{array}$} & \multirow{2}{*}{$\begin{array}{c}\begin{array}{c}\text { Peroxide } \\
\text { value }\end{array} \\
\mathrm{meq}_{2} / \mathrm{kg} \\
\end{array}$} & \multirow{2}{*}{$\frac{\text { Concentration }}{\%}$} & \multirow{2}{*}{$\begin{array}{c}\text { Temperature } \\
{ }^{\circ} \mathrm{C}\end{array}$} & \multirow{2}{*}{$\frac{\text { Time }}{\min }$} & \multicolumn{3}{|c|}{ Real values (coded) } & \multirow{2}{*}{$\begin{array}{l}\text { Run } \\
\text { no. }\end{array}$} \\
\hline & & & & & & & & & & $\mathrm{X}_{3}$ & $\mathrm{X}_{2}$ & $\mathrm{X}_{1}$ & \\
\hline 1.85 & 2.49 & 3.03 & 0.072 & 9.28 & 4.95 & 2.21 & 0.8 & 120 & 35 & 0 & 2 & 0 & 1 \\
\hline 1.83 & 2.48 & 2.87 & 0.072 & 12.56 & 5.59 & 3.49 & 0.8 & 80 & 35 & 0 & -2 & 0 & 2 \\
\hline 1.81 & 2.51 & 3.22 & 0.085 & 4 & 1.77 & 1.17 & 1.2 & 100 & 35 & 2 & 0 & 0 & 3 \\
\hline 1.82 & 2.48 & 3.12 & 0.079 & 7.59 & 3.32 & 1.9 & 1 & 110 & 45 & 1 & 1 & 1 & 4 \\
\hline 1.85 & 2.53 & 3.08 & 0.072 & 13.16 & 5.18 & 3.43 & 0.8 & 100 & 55 & 0 & 0 & 2 & 5 \\
\hline 1.8 & 2.53 & 3.03 & 0.072 & 10.93 & 5.27 & 2.87 & 0.8 & 100 & 35 & 0 & 0 & 0 & 6 \\
\hline 1.84 & 2.47 & 2.82 & 0.066 & 15.39 & 6.82 & 4.02 & 0.6 & 110 & 45 & -1 & 1 & 1 & 7 \\
\hline 1.84 & 2.46 & 2.72 & 0.062 & 19.83 & 8.78 & 5.57 & 0.4 & 100 & 35 & -2 & 0 & 0 & 8 \\
\hline 1.83 & 2.46 & 3.07 & 0.078 & 9.01 & 3.64 & 2.43 & 1 & 90 & 45 & 1 & -1 & 1 & 9 \\
\hline 1.83 & 2.5 & 3.14 & 0.079 & 6.87 & 3.73 & 1.91 & 1 & 90 & 25 & 1 & -1 & -1 & 10 \\
\hline 1.8 & 2.54 & 3.11 & 0.072 & 10.83 & 5.16 & 2.87 & 0.8 & 100 & 35 & 0 & 0 & 0 & 11 \\
\hline 1.8 & 2.54 & 3.08 & 0.071 & 11.04 & 5.31 & 2.88 & 0.8 & 100 & 35 & 0 & 0 & 0 & 12 \\
\hline 1.86 & 2.56 & 3.05 & 0.079 & 5.45 & 3.41 & 1.32 & 1 & 110 & 25 & 1 & 1 & -1 & 13 \\
\hline 1.82 & 2.52 & 2.85 & 0.067 & 17.04 & 7.14 & 4.72 & 0.6 & 90 & 45 & -1 & -1 & 1 & 14 \\
\hline 1.81 & 2.51 & 2.99 & 0.072 & 11.03 & 5.25 & 2.86 & 0.8 & 100 & 35 & 0 & 0 & 0 & 15 \\
\hline 1.81 & 2.52 & 3.02 & 0.073 & 10.95 & 5.17 & 2.82 & 0.8 & 100 & 35 & 0 & 0 & 0 & 16 \\
\hline 1.81 & 2.55 & 3.06 & 0.072 & 10.81 & 5.23 & 2.8 & 0.8 & 100 & 35 & 0 & 0 & 0 & 17 \\
\hline 1.87 & 2.56 & 2.98 & 0.072 & 8.86 & 5.37 & 2.32 & 0.8 & 100 & 15 & 0 & 0 & -2 & 18 \\
\hline 1.84 & 2.48 & 2.91 & 0.067 & 13.11 & 6.91 & 3.43 & 0.6 & 110 & 25 & -1 & 1 & -1 & 19 \\
\hline 1.84 & 2.5 & 2.89 & 0.067 & 14.97 & 7.23 & 4.19 & 0.6 & 90 & 25 & -1 & -1 & -1 & 20 \\
\hline
\end{tabular}

Table 2. Regression coefficients and correlation of fitted models by the central composite design.

\begin{tabular}{|c|c|c|c|c|c|c|c|}
\hline \multirow[b]{2}{*}{ Index } & \multicolumn{7}{|c|}{ Response } \\
\hline & $\begin{array}{c}\text { Peroxide value } \\
\left(\mathrm{meq} \mathrm{O}_{2} / \mathrm{kg}\right)\end{array}$ & Anisidine value & Totox value & $\begin{array}{c}\text { Free fatty acid } \\
(\% \text { oleic acid })\end{array}$ & $\begin{array}{c}\text { Rancimat } \\
(\mathrm{h})\end{array}$ & $A_{232 \mathrm{~nm}}$ & $A_{268 \mathrm{~nm}}$ \\
\hline $\mathrm{B}_{1}$ & $0.28^{\star}$ & $-4.56 \mathrm{E}-003^{\star}$ & $+0.07^{\star}$ & $-1.250 \mathrm{E}-004^{\mathrm{ns}}$ & $-0.017^{\mathrm{ns}}$ & $0.013^{\star}$ & $-6.91 \mathrm{E}-003^{*}$ \\
\hline $\mathrm{B}_{2}$ & $-0.32^{*}$ & $-0.02^{*}$ & $-0.11^{\star}$ & $0.000^{\mathrm{ns}}$ & $-7.50 \mathrm{E}-004^{\mathrm{ns}}$ & $0.022^{\text {ns }}$ & $-0.02^{\mathrm{ns}}$ \\
\hline $\mathrm{B}_{3}$ & $-1.1^{\star}$ & $-8.76^{\star}$ & $-33.58^{\star}$ & $5.87 \mathrm{E}-003^{\star}$ & $0.50000^{\star}$ & $-0.089^{\text {ns }}$ & $-0.18^{\mathrm{ns}}$ \\
\hline $\mathrm{B}_{11}$ & $6.59 \mathrm{E}-003^{\mathrm{ns}}$ & - & $+1.82 \mathrm{E}-004^{\mathrm{ns}}$ & $3.41 \mathrm{E}-005^{\mathrm{ns}}$ & $1.12500 \mathrm{E}-004^{\mathrm{ns}}$ & $1.93 \mathrm{E}-005^{\mathrm{ns}}$ & $1.39 \mathrm{E}-004^{\star}$ \\
\hline $\mathrm{B}_{22}$ & $3.41 \mathrm{E}-004^{\mathrm{ns}}$ & - & $-4.32 \mathrm{E}-005^{\mathrm{ns}}$ & $3.41 \mathrm{E}-005^{\mathrm{ns}}$ & - & $-1.31 \mathrm{E}-004^{*}$ & $8.98 \mathrm{E}-005^{\star}$ \\
\hline $\mathrm{B}_{33}$ & $0.13^{*}$ & - & $+6.1^{\star}$ & $4.09 \mathrm{E}-004^{*}$ & - & $-0.33^{*}$ & $0.13^{*}$ \\
\hline $\mathrm{B}_{12}$ & $0.01^{\mathrm{ns}}$ & - & $+2.62 \mathrm{E}-004^{\mathrm{ns}}$ & $0.00^{\text {ns }}$ & - & $-8.75 \mathrm{E}-005$ & $-2.50 \mathrm{E}-005^{\mathrm{ns}}$ \\
\hline $\mathrm{B}_{13}$ & $-2.5 \mathrm{E}-003^{\mathrm{ns}}$ & - & $-4.37 \mathrm{E}-003^{\mathrm{ns}}$ & $0.00^{\mathrm{ns}}$ & $8.12 \mathrm{E}-003^{\mathrm{ns}}$ & $-8.12 \mathrm{E}-003^{\star}$ & $-1.25 \mathrm{E}-003^{\mathrm{ns}}$ \\
\hline $\mathrm{B}_{23}$ & $0.043^{\star}$ & - & $0.042^{*}$ & $2.500 \mathrm{E}-004^{\mathrm{ns}}$ & $-1.87 \mathrm{E}-003^{\mathrm{ns}}$ & $9.37 \mathrm{E}-003^{\star}$ & $1.38 \mathrm{E}-016^{\mathrm{ns}}$ \\
\hline Adjusted R2 & 0.99 & 0.99 & 0.99 & 0.87 & 0.72 & 0.74 & 0.79 \\
\hline $\begin{array}{l}\text { Adequate } \\
\text { precision }\end{array}$ & 27.64 & 39.39 & 29.37 & 12.78 & 12.38 & 9.53 & 10.33 \\
\hline
\end{tabular}

$\mathrm{B}_{1}=$ Time; $\mathrm{B}_{2}=$ Temperature; $\mathrm{B}_{3}=$ Concentration; ${ }^{\text {nn}}$ Not significant; Significant at ${ }^{*} p \leq 0.0$. 
Moreover, Adj R-Squared: 0.99 and Adeq Precision: 270 showed a suitable fit of the model with the experimental results. Results of the analysis of variance showed that time, temperature, and bleaching clay concentration, as well as the interaction between temperature and the bleaching clay concentration plus the square of concentration, were significant in the equation, thereby showing the effect of such factors on the peroxide value.

\subsection{Anisidine value}

As explained in ISO 6885: 2006 method, anisidine value was studied and the results revealed that the linear regression model was the best one for predicting the effect of the studied factors on the anisidine value. As shown in Table 2, the effects of time, temperature, and bleaching clay concentration on the anisidine value were significant at the $5 \%$ level. According to the obtained model, no results indicated the interaction effect between the factors and the effect of all three factors on anisidine value was a decreasing one. The greatest effect was related to that of the concentration of bleaching clay on the anisidine value.
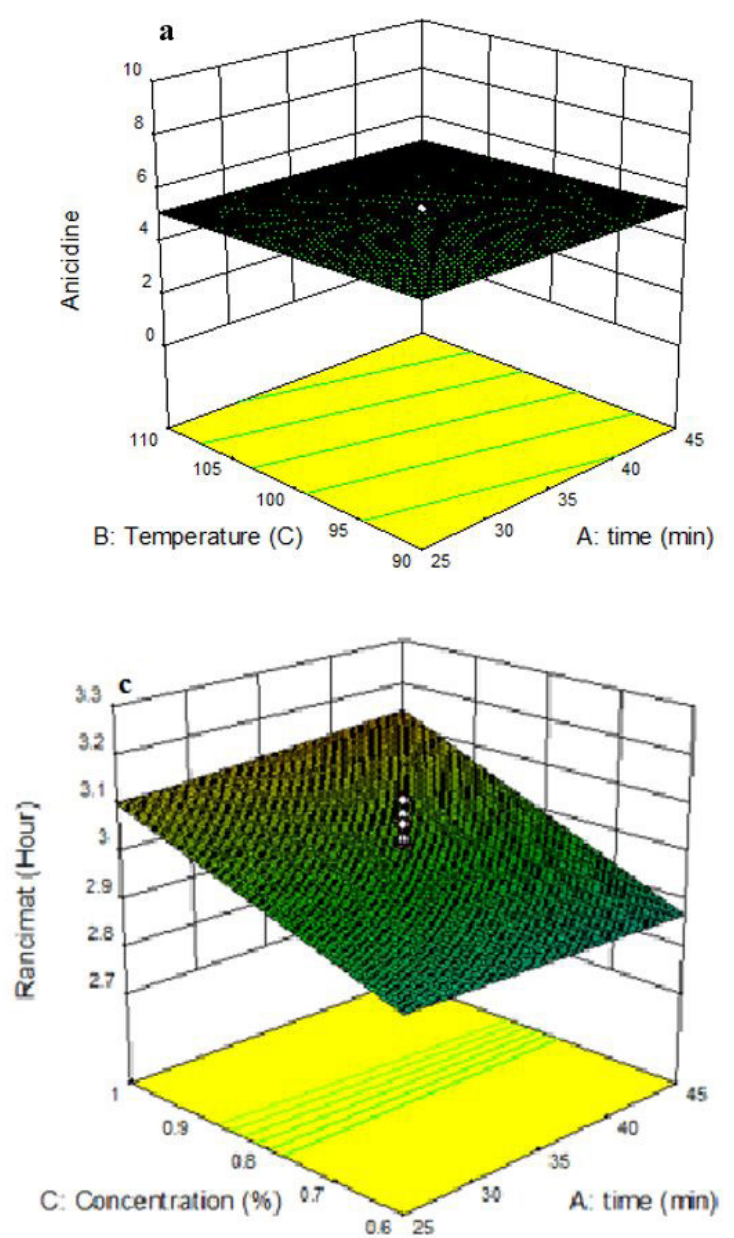

\subsection{Totox value}

According to Equation 1, Totox is a function of peroxide and anicidine value, and due to the higher impact of peroxide value in Totox value, parameters affecting peroxide value were more important than the factors critical for the anicidine value.

As shown in Table 2, the second-order model was significant for the factors of time, temperature, and concentration of bleaching clay, indicating that each factor could have an interaction with other ones and influence the Totox value in addition to having an independent effect on the Totox value. Referring to the analysis of variance table (Table 2), the second-order model was significant and the fitness lack of the insignificant model in the chart matching the results predicted by the model with those obtained by the experiment for the Totox value of bleached oil was Adj R-Squared: 0.99 and Adeq Precision: 297.36. This indicated the high validity of the model in predicting the results.

Referring to Figure $1 \mathrm{~b}$ and Table 2 , it could be seen that the bleaching clay concentration had the most significant impact
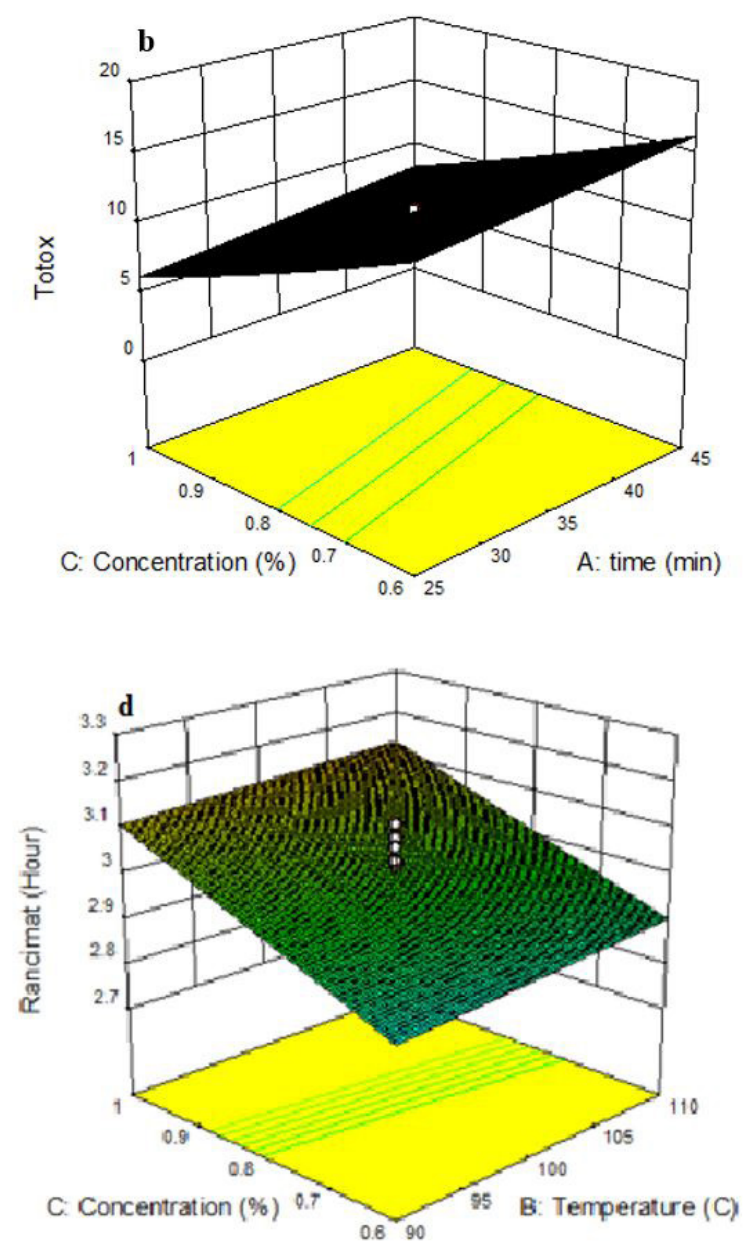

Figure 1. (a) Effect of temperature and heating time on the amount of the anisidine value in the bleaching process; (b) Simultaneous effect of the bleaching clay concentration and temperature on the Totox value; (c) Effect of bleaching time and bleaching clay concentration on the thermal resistance of oil; (d) Effect of Bleaching clay concentration and bleaching temperature on the thermal resistance of oil. 
on the Totox value. With the highest concentration of bleaching clay, the least Totox value was obtained.

The negative linear regression coefficient of the concentration effect of bleaching clay on the Totox value was verified in this point. Time was the next one with an effect on the Totox value; the positive linear regression coefficient $\left(B_{1}\right)$ showed that by increasing the time, the Totox value was raised and the linear effect of temperature on the Totox value was very low; due to the negative linear regression coefficient $\left(B_{2}\right)$, it showed that by increasing the temperature, the Totox value was decreased.

\subsection{Free fatty acid}

As described, free fatty acid was determined using ISO 660: 2009. According to the analysis of variance table (Table 2), the quadratic model was significant and the lack of fitness of the model was also insignificant. Also, Adj R-Squared: 0.98 and Adeq Precision: 55.28 indicated the appropriate fitting of the model with the experimental results. Based on the results, the effect of the bleaching clay concentration as well as its square was significant.

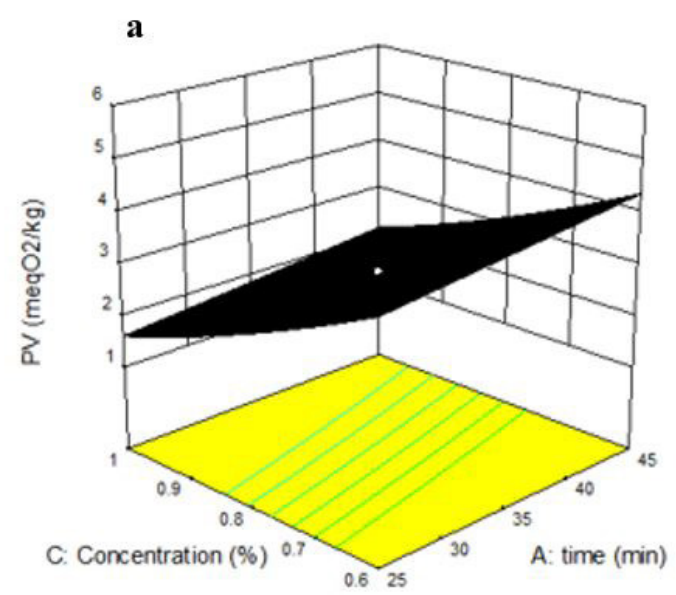

\subsection{Oxidative stability test by Rancimat method}

According to Table 2, a linear model used for the simultaneous effect of temperature, time, and concentration of bleaching clay on the Rancimat value was significant. As shown in Table 2, the effect of temperature and time on the oil shelf life (R/C test per hour) was negligible, such that the effect of these two factors was insignificant.

The greatest effect on the increase of the shelf life was due to the bleaching clay concentration, which clearly increased the shelf life of the oil from 2.8 to more than $3.2 \mathrm{~h}$. With regard to the analysis of variance table, R-Squared $=0.81$ was obtained for this factor, which indicated that the experimental results were in good agreement with the modeling ones. As shown in Figure 1c and 1d, the concentration of bleaching clay had an effective role in increasing oxidative stability, which could relate to peroxide value reduction as indicated in Figure 2a.

\subsection{UV specific absorption}

As shown in Table 2, the interaction between time and bleaching clay concentration, the interaction between temperature and bleaching clay concentration and also, the square of temperature

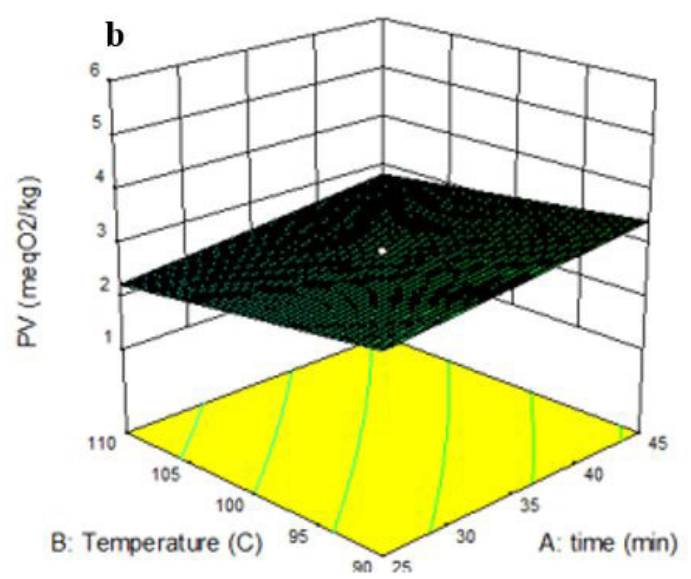

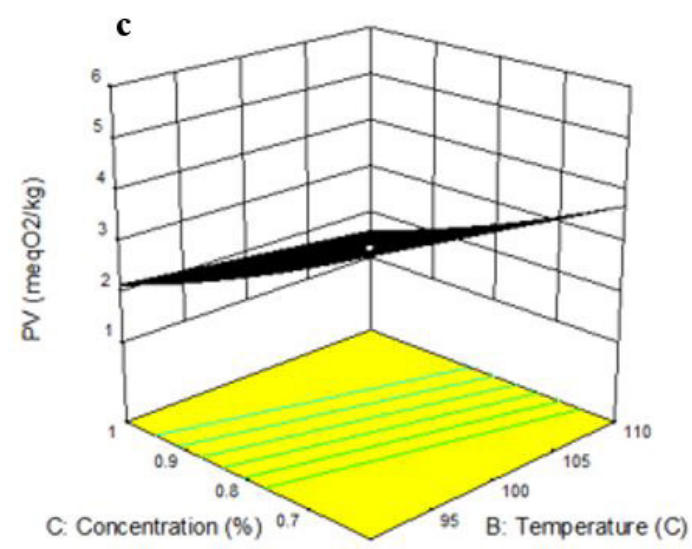

Figure 2. Effect of the factors influencing the changes in the peroxide value: (a) Simultaneous effect of temperature and concentration of the bleaching clay; (b) Simultaneous effect of temperature and heating time; (c) Simultaneous effect of the bleaching clay concentration and the bleaching temperature. 
as well as the concentration were the significant factors on the absorption changes at the wavelength of $232 \mathrm{~nm}$; the time was the only significant independent factor in this index.

As shown in Figure $3 \mathrm{a}$ and $3 \mathrm{~b}$, with the increase in the bleaching time, the absorption was decreased at $232 \mathrm{~nm}$, showing the absorption of the oxidation products over time. Also, the concentration of bleaching clay had some interaction with other factors; the interaction of time/concentration of the bleaching clay and the temperature/the concentration of bleaching clay could significantly reduce the effect of important factors with the $232 \mathrm{~nm}$ absorption.

Regarding the $268 \mathrm{~nm}$ absorption, the effect of time as an independent factor was significant; in addition, the square of all the factors was significant. According to the results obtained at temperatures less and higher than 110 degrees, as well as times less than $25 \mathrm{~min}$ and more than $45 \mathrm{~min}$, the absorption rate was increased. The less time could be attributed to the insufficient absorption of the factors affecting the bleaching clay, while the higher one might be related to forming more oxidation products.
As shown in Figure $3 \mathrm{c}$ and $3 \mathrm{~d}$, the concentration of above $0.4 \%$ of the bleaching clay reduced the effective factors in adsorption.

\section{Discussion}

According to the analysis of variance table (Table 2) and Figure 2, it might be concluded that the concentration of the bleaching clay had the greatest effect on the reduction of the peroxide value and the temperature was the next important factor; this was consistent with the results obtained by Skevin et al. (2012). Both the concentration of bleaching clay and temperature could have a decreasing effect on the peroxide value.

Although temperature can be regarded as an increasing factor in the peroxide value, the reduction of the peroxide value could be explained by the reduction of oil viscosity due to temperature and the more appropriate relationship with the bleaching clay. According to the results, it was observed that the effect of the formation of the initial oxidation products over time was greater than that of the adsorption of oxidation products on the bleaching clay (Equation 3). On the other hand,
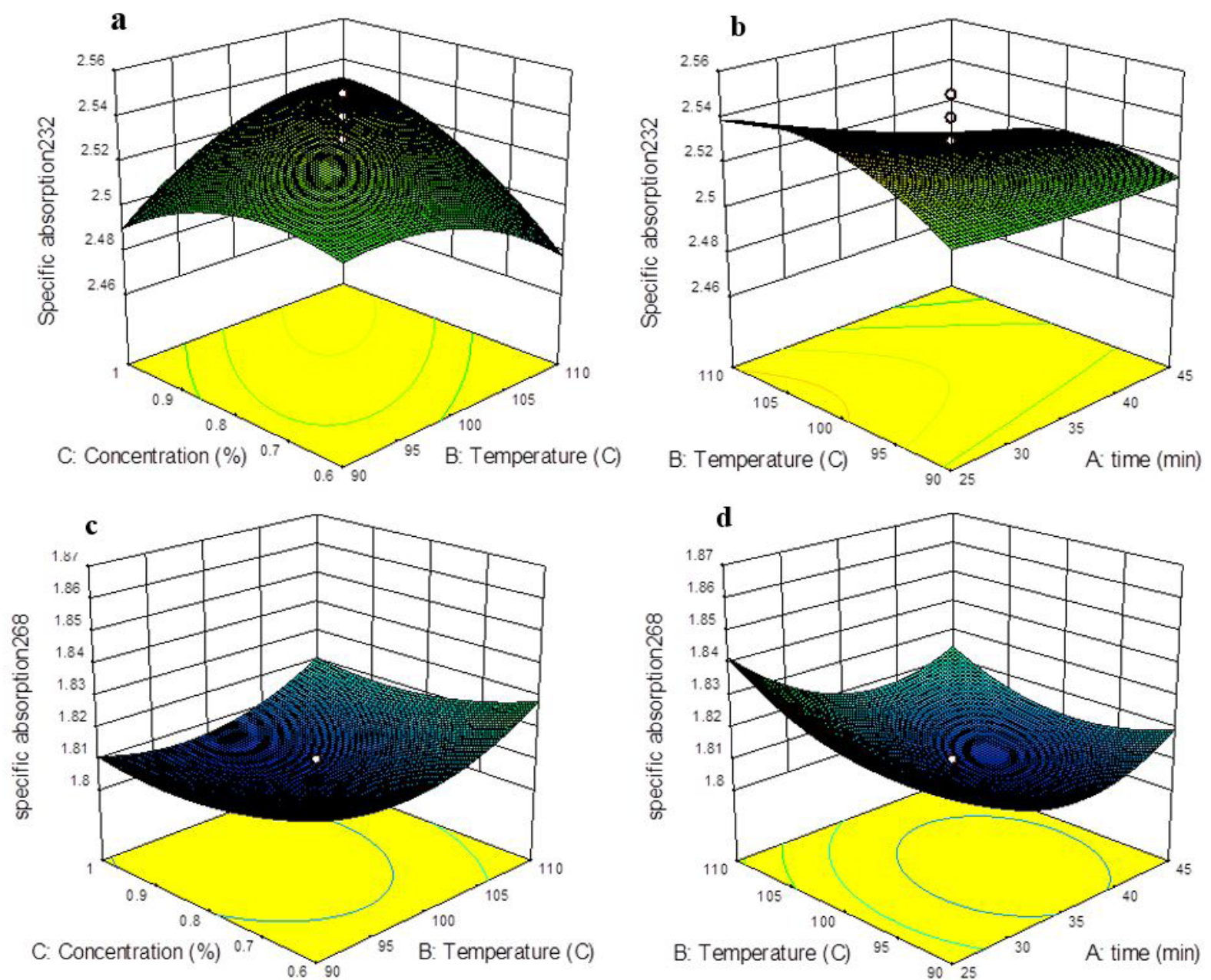

Figure 3. (a) Effects of bleaching temperature and the concentration of the bleaching clay on the specific absorption at $232 \mathrm{~nm}$; (b) Effects of temperature and time of bleaching on the specific absorption at $232 \mathrm{~nm}$; (c) Effects of bleaching temperature and the bleaching clay concentration on the specific absorption at $268 \mathrm{~nm}$; (d) Effects of temperature and time on the specific absorption at $268 \mathrm{~nm}$. 
temperature, due to its simultaneous effect on the diffusion coefficient (D), demonstrated that its effect on increasing the absorption of oxidation raw materials in the bleaching clay was more than that on the creation of the initial oxidation products.

$\frac{m B}{A}=-D \frac{\partial c}{\partial x}$

In Equation 3, $\mathrm{m}_{\mathrm{B}}$ is the mass velocity of the particle flow B $(\mathrm{kg} / \mathrm{hr}), \mathrm{c}$ is the concentration $\mathrm{B}\left(\mathrm{kg} / \mathrm{m}^{3}\right)$ or the number of moles per unit volume $\left(\mathrm{kg}-\mathrm{mol} / \mathrm{m}^{3}\right)$, D is the propagation factor $\left(\mathrm{m}^{2} / \mathrm{s}\right)$, and $\mathrm{A}$ is the area $\left(\mathrm{m}^{2}\right)$.

$D=\frac{k B T}{6 \pi \eta r}$

where: $k_{B}$ is Boltzmann's constant; $T$ is the absolute temperature; $\eta$ is the dynamic viscosity; $r$ is the radius of the particle.

As shown in Table 2 and Figure 1a, the concentration of the bleaching clay had the significant effect of $5 \%$ on the anisidine value. Also, the time coefficient was minimum, which could be interpreted according to the mechanism of the absorption of the material in the bleaching clay. This absorption mechanism might be expressed in the Fick's law (Equation 3).

As is clear from this equation, time had a linear effect on the adsorption of substances and their propagation on the surface of the bleaching clay. In the interpretation of the results obtained as well as the difference between these results and those of Skevin et al. (2012), two effects for time can be assumed; 1. Intensification of the secondary products of oxidation (the positive effect), 2. Linear effect on the absorption increase of materials on the surface of the bleaching clay according to Equation 3 (the adverse effect). Naturally, due to the bleaching conditions and the initial conditions of the oil, depending on the effect, which was higher, the positive or negative effect of the temperature on radical formation could be expected.

Referring to Table 2, after the bleaching clay, the temperature had the greatest effect on reducing the anisidine value. According to the Stokes-Einstein studies, viscosity can have a reversible effect on propagation. As can be seen from the Stokes-Einstein equation (Equation 4), the temperature can affect two aspects of the propagation constant: 1 . Direct effect on the propagation constant; 2 . Effect of temperature on viscosity reduction, which can decrease viscosity, according to the Stokes-Einstein equation, thereby increasing the rate of propagation. Since the peroxide and anisidine values each are a part of the oxidation determination of oils, the Totox value of the samples was estimated. As can be seen in the Totox value equation (Equation 1), the Totox value was the sum of two times of the peroxide value with the anisidine one. Therefore, the effect of the effective parameters on the peroxide value could be higher than that of the anisidine, based on the changes in the Totox value.

Therefore, it could be expected that the effect of the factors involved in the changes in peroxide value and their coefficients in the Totox value would be more visible. As can be observed in the equation of the peroxide and anisidine values, the temperature and concentration of the bleaching clay had a decreasing effect on each index; so, it could be expected that the Totox value would have the same effect.

According to Figure 1b, the time had a positive effect on the Totox value; therefore, the effect of time on the two parameters of the peroxide and anisidine values could be considered. As shown in Table 2, the time had a positive effect on the peroxide value with a higher coefficient; thus, its positive effect on the Totox value was evident.

Based on Table 2, the bleaching clay concentration was the primary determining factor for free fatty acid during sunflower oil bleaching. In Figure 4, the effect of increasing the concentration of the bleaching clay could be observed, while the effect of temperature and time was not significant. The lowest free fatty acid with $0.4 \%$ bleaching clay was obtained at the temperature of $100^{\circ} \mathrm{C}$ and time of $35 \mathrm{~min}$. Although the bleaching process does not normally increase the amount of free fatty acid (Zschau, 2000), this minor increase may be related to the type of bleaching clay, given the point that acid-activated bleaching clay was used in this study. These results were consistent with those obtained by Skevin et al. (2012). According to their results, the increase in free fatty acid in the samples was minimum during bleaching with the relative increase of $1 \%$, indicating that the bleaching clay was suitable for oil bleaching.

Since oxidation is increasingly expanded at the progress stage, removing the primary and secondary oxidation products can be effective for maintaining the oils during the oxidation process and increasing the shelf life of the oil. As can be observed in the peroxide, anisidine, and Totox values, the concentration of bleaching clay had the greatest effect on the decrease of the values of peroxide, anisidine, and Totox (its coefficient was more than that of other factors).

In the analysis of the results (Table 2 and Figure $1 \mathrm{c}$ and $1 \mathrm{~d}$ ), regarding the stability of oils with the Rancimat test, it was observed that concentration was the only significant factor among all the studied factors. The insignificance of the lack of fit for this factor indicated the optimal fit of the proposed model with the experimental results.

The decomposition of hydroperoxides and isomerization of unsaturated fatty acids led to the formation of conjugated dienes and trienes, which showed the maximum absorption at $262 \mathrm{~nm}$ and $268 \mathrm{~nm}$, respectively. These compounds, which are highly unstable under oxidation, are much more sensitive than oleic and linoleic acids; so, bleaching parameters should be optimized to prevent the formation of these compounds.

As shown in Table 3, considering the optimal values for bleaching operations, $86.7 \%$ of desirable condition to reduce primary and secondary oxidation products can be obtained. Table 3 shows the optimal values of each of the parameters as well as the experimental and predicted values of each of the factors based on the mathematical model.

The optimal values obtained by the RSM method were tested in practice in 3 replications, with the optimal and experimental results presented in Table 3. As can be observed, the empirical results indicated there was no difference between the optimal values and the values obtained by the 

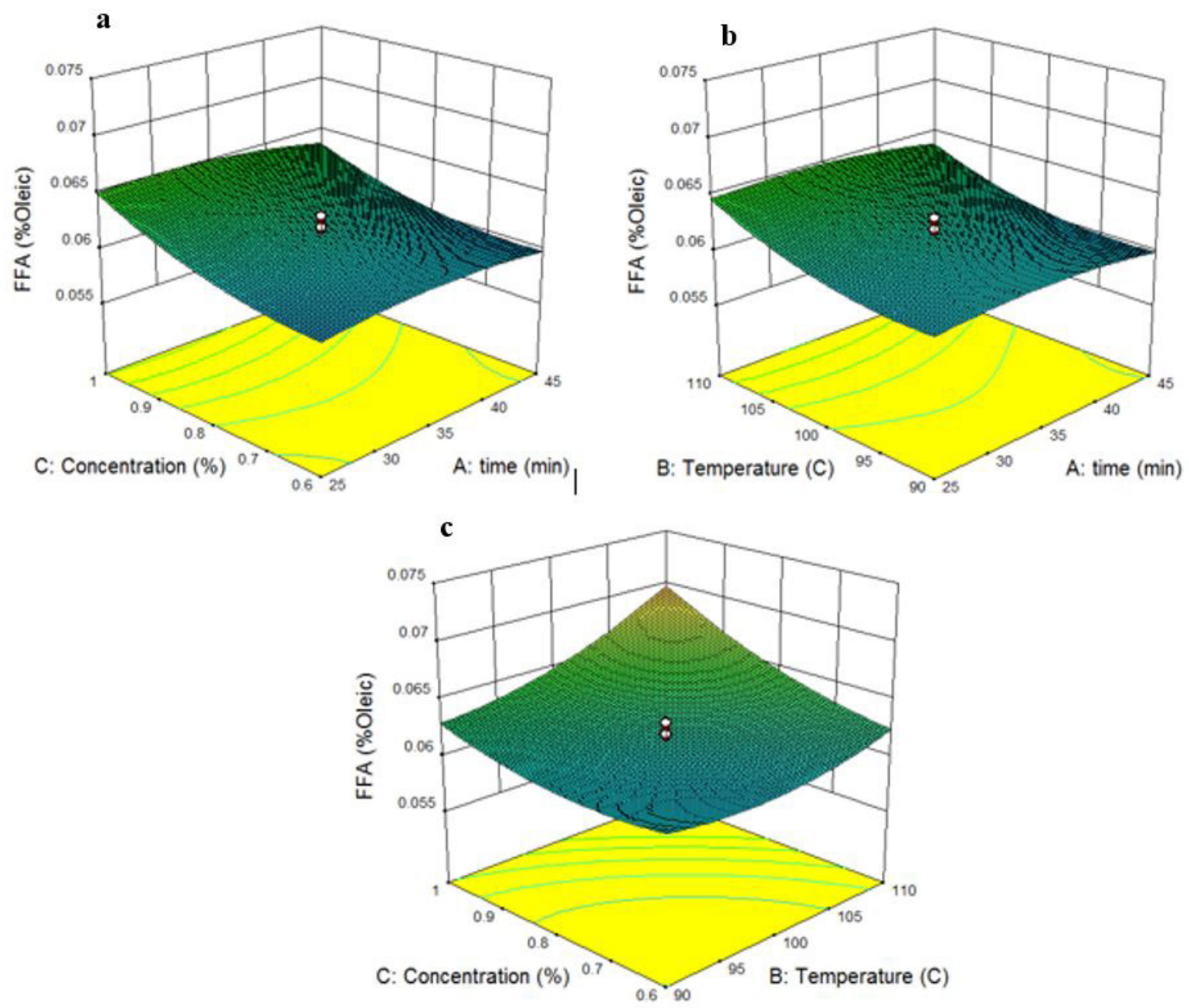

Figure 4. Effect of the studied factors on the free fatty acid in the bleaching process: (a) Bleaching clay concentration and time; (b) Temperature and the bleaching time; (c) Bleaching clay concentration and bleaching temperature.

Table 3. Comparison of the optimum and experimental values in practice.

\begin{tabular}{|c|c|c|}
\hline \multicolumn{2}{|c|}{ Optimum value } & Variables \\
\hline \multicolumn{2}{|c|}{37.41} & Time (min) \\
\hline \multicolumn{2}{|c|}{92.73} & Temperature $\left({ }^{\circ} \mathrm{C}\right)$ \\
\hline \multicolumn{2}{|c|}{1.17} & Concentration (\%) \\
\hline $0.07 \pm 1.52$ & 1.48 & Peroxide value $\left(\right.$ meq $\left.\mathrm{O}_{2} / \mathrm{kg}\right)$ \\
\hline $0.16 \pm 2.03$ & 2.08 & Anisidine value \\
\hline $0.21 \pm 3.12$ & 3.22 & Rancimat (h) \\
\hline $0.13 \pm 2.41$ & 2.45 & $A_{232 \mathrm{~nm}}$ \\
\hline $0.07 \pm 1.76$ & 1.82 & $A_{268 \mathrm{~nm}}$ \\
\hline
\end{tabular}

empirical method; this could be achieved in practice by the results provided through the RSM method. Therefore, the results obtained in this study could also be applicable to the practical scale.

In the conventional process, time, temperature, and bleaching clay concentration was set at $30 \mathrm{~min}, 95^{\circ} \mathrm{C}$, and $3 \%$, respectively (Salawudeen et al., 2014). According to the results of this study, the temperature and concentration of the bleaching clay could be reduced to $92.73{ }^{\circ} \mathrm{C}$ and $1.18 \%$. This reduction could save energy and resources also reduce environmental pollution. Fitting the experimental results with the optimal ones provided by the Design Expert, ver. 10, also indicated that the results obtained by the RSM method were consistent with the practical conditions. 


\section{Conclusions}

Optimization of the model using the RSM method showed that, to achieve the optimal conditions, setting time on $37.31 \mathrm{~min}$, temperature at $92.7^{\circ} \mathrm{C}$, and clay concentration at $1.18 \%$ could meet $86.7 \%$ of the expectations to reduce the useful factors on the oxidation, carried out during bleaching while keeping the qualitative properties of the oil.

Overall, the results of this study showed the possibility of saving time and resources by optimizing the process of bleaching. As seen, statistical methods such as RSM could minimize the use of resources (fuel) by reducing the temperature from $100^{\circ} \mathrm{C}$ to $92.7^{\circ} \mathrm{C}$. At the same time, by upgrading the process time, the capacity of the plant could be increased. Further, based on the results of this study, the consumption of bleaching clay was dropped to $39 \%$ of the initial amount; this could save the environment in addition to reducing the consumption of resources.

\section{References}

Ajemba, R. O., Igbokwe, P. K., \& Onukwuli, O. D. (2013). Optimization of color pigments removal from palm oil by activated Ukpor clay using response surface methodology. Journal of Applied Science, Engineering and Technology, 6, 423-432. http://dx.doi.org/10.19026/rjaset.6.4096.

Didi, M. A., Makhoukhi, B., Azzouz, A., \& Villemin, D. (2007). Colza oil bleaching through optimized acid activation of bentonite: a comparative study. Applied Clay Science, 42(3-4), 336-344. http:// dx.doi.org/10.1016/j.clay.2008.03.014.

Fennema, O. R. (1996). Food chemistry (3rd ed., Chapt. 5). New York: Marcel Dekker.

Hatami, A. M., Sabour, M. R., \& Amiri, A. (2018). Recycling process of spent bleaching clay: optimization by response surface methodology. Global Journal of Environmental Science and Management, 4(1), 9-18. http://dx.doi.org/10.22034/gjesm.2018.04.01.002.

International Organization for Standardization - ISO. (1994). ISO/ DIS, 6886.2: animal and vegetable fats and oils-Determination of oxidation stability: accelerated oxidation test. Geneva.

International Organization for Standardization - ISO. (2006). ISO method 6885:2006: animal and vegetable fats and oils: determination of anisidine value. Geneva.

International Organization for Standardization - ISO. (2007). ISO method 3960:2007: animal and vegetable fats and oils: determination of peroxide value: iodometric (visual) endpoint determination. Geneva.
International Organization for Standardization - ISO. (2009). ISO method 660:2009: animal and vegetable fats and oils: determination of acid value and acidity. Geneva.

International Organization for Standardization - ISO. (2011). ISO method 3656:2011: animal and vegetable fats and oils: determination of ultraviolet absorbance expressed as specific UV extinction. Geneva.

Moghaddam, S., Zerafat, M. M., \& Sabbaghi, S. (2018). Response surface methodology for optimization of Phenol photocatalytic degradation using Carbon-doped $\mathrm{TiO} 2$ nano-photocatalyst. International Journal of Nanodimension, 9(1), 89-103.

Mozafari, H. R., Hosseini, E., Hojjatoleslamy, M., Mohebbi, G. H., \& Jannati, N. (2017). Optimization low-fat and low cholesterol mayonnaise production by central composite design. Journal of Food Science and Technology, 54(3), 591-600. http://dx.doi.org/10.1007/ s13197-016-2436-0. PMid:28298672.

Mukasa-Tebandeke, I.-Z., Ssebuwufu, P. J. M., Nyanzi, S. A., Schumann, A., Nyakairu, G. W., \& Lugolobi, F. (2014). Using trace metals, peroxide, acid and iodine values to characterize oils bleached using clays from central and Eastern Uganda. American Journal of Analytical Chemistry, 5(17), 1302-1312. http://dx.doi.org/10.4236/ ajac.2014.517136.

Nwabanne, J. T., \& Ekwu, F. C. (2013). Experimental design methodology applied to bleaching of palm oil using local clay. International Journal of Applied Science and Technology, 3, 69-70.

Okolo, J. C., \& Adejumo, B. A. (2014). Effect of bleaching on some quality attributes of crude palm oil. Journal of Engineering, 4, 25-27. http://dx.doi.org/10.9790/3021-041203025028.

Salawudeen, T. O., Arinkoola, A. O., Jimoh, M. O., \& Akinwande, B. A. (2014). Clay characterization and optimisation of bleaching parameters for palm kernel oil using alkaline activated clays. Journal of Minerals \& Materials Characterization \& Engineering, 2(6), 586597. http://dx.doi.org/10.4236/jmmce.2014.26060.

Skevin, D., Domijan, T., Kraljic, K., Gajdoš, J., Neđeral, S., \& Obranovi, M. (2012). Optimization of bleaching parameters for soybean oil. Food Technology and Biotechnology, 50(2), 199-207.

Wanasundara, P. K. J. P. D., \& Shahidi, F. (2005). Antioxidants: science, technology, and applications. In F. Shahidi (Ed.), Bailey's industrial oil and fat products (6th ed.). Hoboken: Wiley-Interscience Publication. http://dx.doi.org/10.1002/047167849X.bio002.

Zschau, W. (2000). Bleaching. In R. D. O’Brien, W. E. Farr \& P. J. Wan (Eds.), Introduction to fats and oils technology (2nd ed., pp. 158-178). Champaign: AOCS Press. 